\title{
Hydrogen storage and delivery: immobilization of a highly active homogeneous catalyst for the decomposition of formic acid to hydrogen and carbon dioxide
}

\author{
Weijia Gan • Paul J. Dyson • Gábor Laurenczy
}

Received: 20 September 2009/ Accepted: 25 October 2009/Published online: 7 November 2009 (C) Akadémiai Kiadó, Budapest, Hungary 2009

\begin{abstract}
The homogeneous catalytic system, based on water-soluble ruthenium(II)TPPTS catalyst (TPPTS = meta-trisulfonated triphenylphosphine), selectively decom poses $\mathrm{HCOOH}$ into $\mathrm{H}_{2}$ and $\mathrm{CO}_{2}$ in aqueous solution. Although this reaction results in only two gas products, heterogeneous catalysts could be advantageous for recycling, especially for dilute formic acid solutions, or for mobile, portable applications. Several approaches have been used to immobilize/solidify the homogeneous ruthenium-TPPTS catalyst based on ion exchange, coordination and physical absorption. The activity of the various heterogeneous catalysts for the decomposition of formic acid has been determined. These heterogenized catalysts offer the advantage of easy catalyst separation/recycling in dilute formic acid, or for mobile, portable applications.
\end{abstract}

Keywords Hydrogen storage - Formic acid decomposition ·

Homogeneous catalysis · Catalyst immobilization · Ruthenium · TPPTS

\section{Introduction}

The worldwide demand for energy continues to increase while the global reserves of fossil fuels diminish [1]. Moreover, serious damage to the environment, both physical and atmospheric, has been caused by the rapid consumption of fossil fuels [2]. As an alternative energy carrier, hydrogen has attracted increasing attention for both environmental and economic reasons [3]. However, due to storage and delivery

Dedicated to Prof. Ferenc JOÓ on the occasion of his 60th birthday, a good friend and a fine chemist.

W. Gan · P. J. Dyson · G. Laurenczy $(\bowtie)$

Institut des Sciences et Ingénierie Chimiques, École Polytechnique Fédérale de Lausanne (EPFL),

1015 Lausanne, Switzerland

e-mail: gabor.laurenczy@epfl.ch 
problems for mobile and small applications, the actual use of hydrogen as a transportation fuel is still limited. Until now, none of the existing methods, such as liquid hydrogen tank systems, compressed gas cylinders, carbon nanotubes, metal hydrides and metal-organic frameworks, etc., are entirely satisfactory with respect to reversibility, recycling, weight and safety issues $[4,5]$. Formic acid $(\mathrm{HCOOH})$, which contains $4.4 \%$ of hydrogen, and the formate salt $\left(\mathrm{HCOO}^{-}\right)$have been considered as potential hydrogen-storage materials for many years [6]. Formic acid can decompose in two ways: dehydrogenation (Eq. 1) and dehydration (Eq. 2); the former dehydrogenation reaction is useful for hydrogen storage, whereas the carbon monoxide gas produced in the latter reaction occupies coordination sites of the metal center and causes catalyst poisoning in PEM (proton exchange membrane) fuel cells. In general, the former (desired) reaction takes place under catalytic conditions and the latter reaction is thermally driven and therefore occurs, and becomes important at high temperatures.

$$
\begin{aligned}
& \mathrm{HCOOH} \rightarrow \mathrm{H}_{2}+\mathrm{CO}_{2} \\
& \mathrm{HCOOH} \rightarrow \mathrm{H}_{2} \mathrm{O}+\mathrm{CO}
\end{aligned}
$$

Extensive studies have been carried out on the decomposition of formic acid into $\mathrm{H}_{2}$ and $\mathrm{CO}_{2}$ using heterogeneous metal and metal oxide catalysts [7-10] and under homogeneous conditions using soluble metal complexes as catalysts [11-14]. The existing catalysts are not ideal in that they are not very stable and consequently exhibit limited lifetimes, and they tend to be not very selective [15].

Very recently there has been considerable activity in this area, and much progress has been made, with some notable homogeneous catalysts having been reported. A homogeneous catalytic system based on water-soluble ruthenium(II) phosphine catalysts has been reported [16], which selectively decomposes $\mathrm{HCOOH}$ into $\mathrm{H}_{2}$ and $\mathrm{CO}_{2}$ in aqueous solution. Carbon monoxide free hydrogen has been generated in a very wide pressure range, over prolonged periods, overcoming the limitations of other catalysts $[17,18]$. Beller et al. have also found that a number of ruthenium complexes with arene and phosphine ligands catalyze the selective cleavage of $\mathrm{HCOOH}$ into $\mathrm{H}_{2}$ and $\mathrm{CO}_{2}$ [19-22]. The rate of the decomposition was influenced by the nature and the concentration of the amines presenting in the reaction mixture. Wills et al. suggested [23] that the reaction mechanism of the decomposition of formic acid in a $\mathrm{HCOOH} / \mathrm{Et}_{3} \mathrm{~N}$ azeotrope using a $\mathrm{Rh}$ TsDPEN tethered catalyst, is closely related to of the mechanism in operation in the asymmetric transfer hydrogenation of ketones. Fukuzumi et al. [24] have also shown that formic acid can be decomposed selectively in aqueous solution using a homogeneous catalyst, i.e. $\left[\mathrm{Rh}\left(\mathrm{Cp}^{*}\right)(\mathrm{bpy})\left(\mathrm{H}_{2} \mathrm{O}\right)\right]^{2+}$.

Homogeneous catalysts have some attractive properties/advantages, such as high selectivity and comparatively low activation energies. However, the utility of homogeneous catalysts is limited by separation problems, especially in dilute solutions, or for mobile/portable applications [25]. Combining the advantages of homogeneous and heterogeneous catalysts using liquid (biphasic) [26-31] or solid (heterogeneous) [32, 33] supports has received considerable attention for many years. Numerous approaches to immobilize homogeneous catalysts on solid 
supports have been developed including anchoring, encapsulation techniques and precipitation of products/catalysts by solvent selection and/or the manipulation of physical parameters [32-36]. Nevertheless, comparatively few immobilized homogeneous catalysts are used in industrial processes [37].

Herein we present several approaches that have been used to immobilize/solidify the recently developed homogeneous $\mathrm{Ru}$ (II) catalyst [38]. In aqueous solution, formic acid decomposition is carried out using this hydrophilic ruthenium based catalysts, generated from the highly water-soluble ligand meta-trisulfonated triphenylphosphine (TPPTS) and $\mathrm{RuCl}_{3}$ salt in 2:1 ratio. The resulting ruthenium bis-TPPTS complex, $\left[\mathrm{Ru}(\mathrm{TPPTS})_{2}\right]^{4-}$, is negatively charged. Based on ion exchange, coordination or absorption, the catalyst has been immobilized/solidified on different solid supports.

\section{Experimental section}

\section{Materials}

TPPTS was prepared according to a literature method [39], and contained ca. 10\% of the phosphine oxide. All other reagents were obtained from commercial sources and were used without further purification: ruthenium (III) chloride hydrate (99\%, Platinum Metals Online, Australia), formic acid (98-100\%, Merck KGaA), sodium formate salt (99\%, Acros Organics), Dowex 1X2 chloride form ion exchanger p.a., 200-400 mesh (Fluka), silver nitrate ( $>99 \%$, Sigma-Aldrich), triphenylphosphine polymer bound, $3.2 \mathrm{mmol} / \mathrm{g}$ P loading, 2\% DVB (100-200 mesh, Fluka Analytical), (4-hydroxyphenyl) diphenylphosphine polymer bound, 1.5-2.0 mmol/g P loading, 1\% DVB (50-100 mesh, Aldrich), zeolites (Zeochem AG), toluene (GR for analysis, Merck KGaA).

\section{Kinetic studies}

Kinetic measurements were performed in $10 \mathrm{~mm}$ external diameter medium pressure sapphire NMR tubes [40, 41]. For a typical formic acid decomposition reaction with homogeneous catalysts, $\mathrm{RuCl}_{3}-x \mathrm{H}_{2} \mathrm{O}(0.056 \mathrm{mmol}, 14.7 \mathrm{mg})$ was dissolved in a formic acid/sodium formate $(9: 1,10 \mathrm{M})$ aqueous solution $(1 \mathrm{~mL}$ $\left.\mathrm{H}_{2} \mathrm{O}\right)$, which contains TPPTS $(0.105 \mathrm{mmol}, 64 \mathrm{mg})$. The catalytically active species were formed by heating the sapphire tube at $90{ }^{\circ} \mathrm{C}$ [42] in an electric heating jacket, and the decomposition reaction was monitored via the pressure increase. The recycling experiments were performed by addition of formic acid (10 mmol, $0.38 \mathrm{~mL}$ ), after which the tube was cooled to room temperature and depressurized.

Preparation of heterogenized catalyst via ion exchange

Dowex ion exchange resin $(1 \mathrm{~g})$ was washed with $\mathrm{HCOOH} / \mathrm{HCOONa}$ aqueous solution $(1: 1,0.2 \mathrm{M})$ until no chloride could be detected with $\mathrm{AgNO}_{3}(1 \%$ aqueous solution), then washed with double distilled water until the washings reached a $\mathrm{pH}$ 
of four (tested by $\mathrm{pH}$ test paper special 0-6). The resin was reacted with the active ruthenium catalyst $(0.056 \mathrm{mmol})$, followed by a washing with water $(20 \mathrm{~mL})$. All washings were analyzed using XRF spectroscopy for leaching. No ruthenium was found in the washings, indicating that ruthenium concentration in the resin was $0.056 \mathrm{mmol} / \mathrm{g}$.

Preparation of heterogenized catalyst via ion coordination to a phosphine containing polymer

Immobilization of Ru/TPPTS on a functionalized polymer was carried out under inert atmosphere by using Schlenk and glovebox techniques. $\mathrm{PPh}_{3}$-polymer $(0.1 \mathrm{~g})$, or $\mathrm{PPh}_{3}-O$-polymer $(0.09 \mathrm{~g}), \mathrm{RuCl}_{3}-x \mathrm{H}_{2} \mathrm{O}(0.16 \mathrm{mmol}, 42 \mathrm{mg})$, or $\mathrm{RuCl}_{3}-x \mathrm{H}_{2} \mathrm{O}$ $(0.070 \mathrm{mmol}, 18.4 \mathrm{mg})$ for the $\mathrm{PPh}_{3}-\mathrm{O}$-polymer, and toluene $(30 \mathrm{~mL}$, degassed) were stirred for $3 \mathrm{~h}$ at room temperature. After filtration under nitrogen, the product was dried in vacuum. According to the XRF results, no ruthenium was found in the toluene solvent, and there was no ruthenium leaching in the reaction systems, so the ruthenium concentrations in $\mathrm{PPh}_{3}$-polymer and $\mathrm{PPh}_{3}-O$-polymer were 1.6 and $0.782 \mathrm{mmol} / \mathrm{g}$.

Preparation of heterogenized catalyst via physical absorption

Five different types of zeolites were used to immobilize the ruthenium complexes. Typical formic acid decomposition in homogeneous phase was carried out first and recycled for at least five times. The stable and active ruthenium catalysts were obtained after this activation period. After addition of further $\mathrm{HCOOH}(10 \mathrm{mmol}$, $0.38 \mathrm{~mL}$ ), the zeolites were added carefully into the aqueous solution containing both the reactants and the catalysts. When all the liquid was absorbed by zeolites, $\mathrm{Ru} / \mathrm{TPPTS}$-zeolite was obtained and used as catalyst in the following cycles of formic acid decomposition.

\section{Results and discussion}

The decomposition of a $10 \mathrm{M}$ formic acid solution to $\mathrm{H}_{2}$ and $\mathrm{CO}_{2}$ is highly efficient at $90{ }^{\circ} \mathrm{C}$ using $56.3 \mathrm{mM} \mathrm{RuCl}_{3}-x \mathrm{H}_{2} \mathrm{O}$ and two equivalents of TPPTS as the catalyst (typically $95 \%$ conversion within 30 min under these conditions). Despite the utility of this homogeneous system it could be advantageous, in certain instances, to have an active heterogeneous catalysts, thus attempts to heterogenize this highly active homogeneous system have been made. Initial attempts to heterogenize the catalyst were based on ion exchange using a Dowex ion exchanger, a strongly basic anion exchange resin, containing trimethylammonium groups (Fig. 1a). Immobilization using this approach could lead to a catalyst that is active over the entire $\mathrm{pH}$ range ( $\mathrm{pH} 0-14)$. The active catalyst was generated according to our method [38] and since it is negatively charged it forms a very strong ionic interaction with the anion exchange resin. Indeed, no ruthenium leaching could be detected by XRF spectroscopy either during the preparation process or during catalytic formic acid 
decomposition. The ruthenium-TPPTS catalyst immobilized on the ion exchanger shows a similar activity in the first cycle to the homogeneous ruthenium catalyst, presumably because the catalyst has effective contact with the reactant. Decomposition of a formic acid/sodium formate solution (10 mmol, 9:1) was achieved in 40 min, reaching ca. 95\% conversion, under the same conditions typically used for the homogeneous system (Fig. 1b). However, recycling of the catalyst, following depressurization and the addition of further formic acid, led to a progressive decrease in the reaction rate after three cycles, although the same conversion may be achieved in less than $3 \mathrm{~h}$.

Reaction of $\mathrm{PPh}_{3}-$ or $\mathrm{PPh}_{3}-\mathrm{O}$-cross-linked polystyrene (Figs. 2a, 3a) with ruthenium(III) chloride leads to coordination of the metal to the phosphine moieties of the polymer. These polymers have been used to covalently immobilize homogeneous ruthenium catalysts previously [43]. The new heterogeneous

(a)<smiles>C=Cc1ccc([N+](C)(C)C)cc1</smiles>

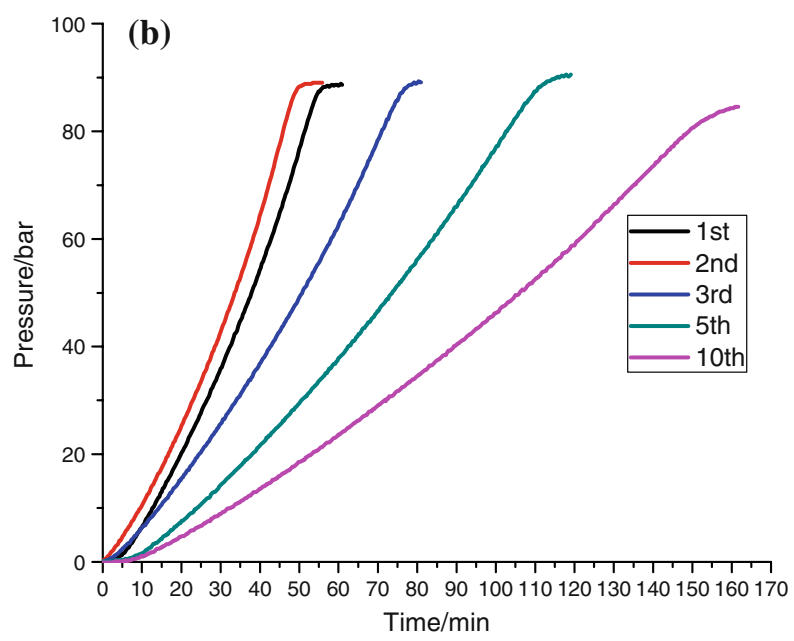

Fig. 1 a Structure of the ion exchange resin monomer: Dowex 1X2 chloride form; $\mathbf{b}$ Kinetic curves for the ruthenium-TPPTS catalyst supported on the ion exchanger (1st, 2nd, 3rd, 5th and 10th cycles). $0.056 \mathrm{mmol} \mathrm{Ru}, 10 \mathrm{mmol} \mathrm{HCOOH} / \mathrm{HCOONa}(9: 1), 1 \mathrm{~g}$ ion exchange resin, $90{ }^{\circ} \mathrm{C}$, addition of $0.38 \mathrm{~mL}$ $\mathrm{HCOOH}$ for recycling. Reaction monitored by pressure increase 
materials were evaluated as catalysts for the decomposition of formic acid and were found to be much less active than the homogeneous system, ca. $8 \mathrm{~h}$ were required to achieve $30-40 \%$ formic acid conversion (Figs. 2b, 3b). It is likely that the reduced activity is due to two main reasons. First, the resulting material is very hydrophobic. Second, the mass transfer of the substrates into the active catalytic sites of the polymer could be rate limiting.

The effect of the presence of zeolites as absorbents on hydrogen production is shown in Fig. 4 and Table 1. To take up the aqueous solutions different quantities of zeolites were added due to their different absorbing ability. The addition of zeolites with stronger absorbing ability, see Table 1 Entry 2 and 5, did not decrease the catalytic activity of the ruthenium complexes. The other zeolites became black (catalyst decomposition) under high pressure and acid environment, and led to much slower reactions.

With the zeolite PB Na-BEA, the catalytic system was recycled by addition of formic acid. The 92nd reaction could achieve 95\% conversion within $30 \mathrm{~min}$

(a)<smiles>c1ccc(-c2ccc(P(c3ccccc3)c3ccccc3)cc2)cc1</smiles>

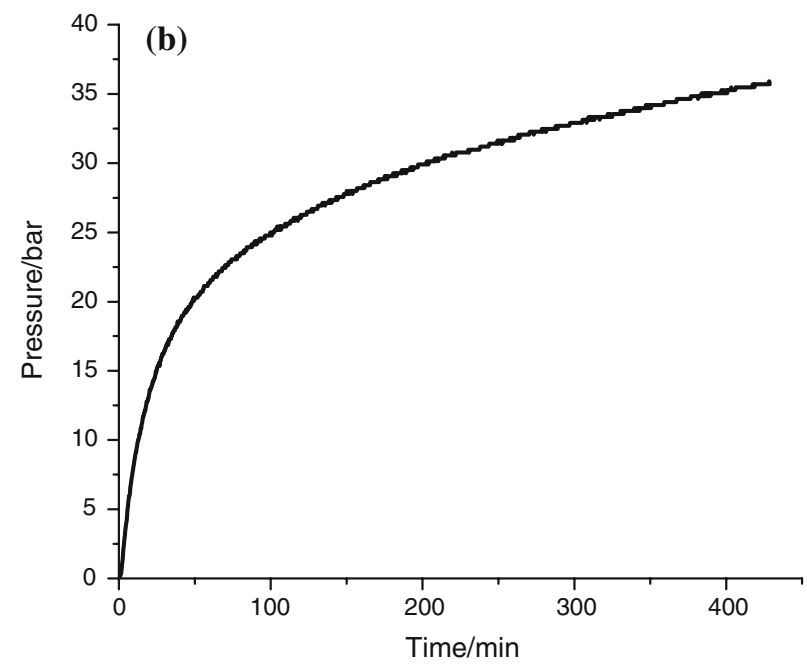

Fig. 2 a Structure of triphenylphosphine, polymer bound; b Kinetic curve for the catalyst $\mathrm{RuCl}_{3}-x \mathrm{H}_{2} \mathrm{O}$ supported on $\mathrm{PPh}_{3}$-polymer (1st cycle). $0.16 \mathrm{mmol} \mathrm{Ru}, 0.1 \mathrm{~g} \mathrm{PPh}$-polymer, $0.38 \mathrm{~mL} \mathrm{HCOOH}, 90{ }^{\circ} \mathrm{C}$ 

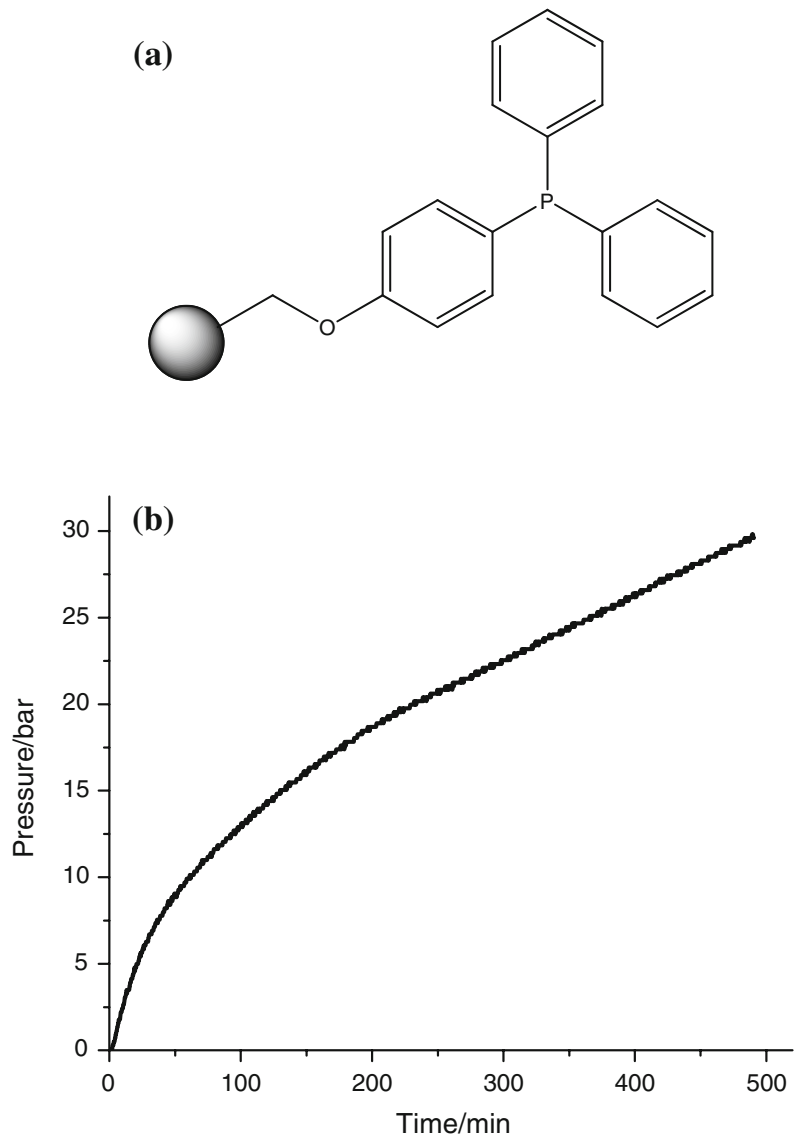

Fig. 3 a Structure of (4-hydroxyphenyl) diphenylphosphine, polymer bound; b Kinetic curve for the catalyst $\mathrm{RuCl}_{3}-x \mathrm{H}_{2} \mathrm{O}$ supported on $\mathrm{PPh}_{3}-O$-polymer. $0.07 \mathrm{mmol} \mathrm{Ru}, 0.09 \mathrm{~g} \mathrm{PPh}_{3}-O$-polymer, $0.38 \mathrm{~mL}$ $\mathrm{HCOOH}, 90{ }^{\circ} \mathrm{C}$, first catalytic cycle

(Fig. 4b Entry 7), which was nearly as same as the homogeneous catalytic reaction (Fig. 4b Entry 1). However, according to the XRF spectra, when the solid catalyst was washed with water, the Ru-TPPTS could be removed gradually, showing that the zeolites here were mainly used as physical absorbents.

\section{Conclusions}

The main objective of this study was to evaluate different methods for the immobilization of the highly water soluble ruthenium(II)-TPPTS formic acid decomposition catalyst. For this purpose, different immobilization/solidification methods, such as ion exchange, polymer immobilization and physical absorption were tested as potential candidates and subsequent catalytic screening was performed. Both ion exchange and coordination to the phosphine-containing 

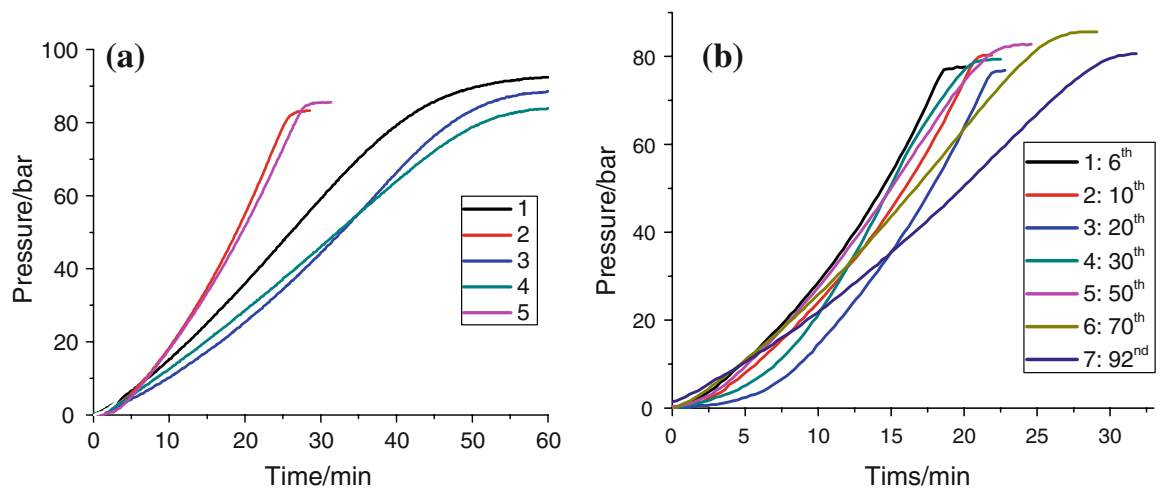

Fig. 4 a Influence of different types of zeolites on the reaction rate. $56.3 \mathrm{mM} \mathrm{Ru}, 2$ eqiuv. phosphine to $\mathrm{Ru}, 10 \mathrm{M} \mathrm{HCOOH} / \mathrm{HCOONa}(9: 1), 90{ }^{\circ} \mathrm{C}$, Entries 1-5 (Table 1); b Kinetic curves of the recycling experiments using the ruthenium-TPPTS catalyst $(0.224 \mathrm{mmol})$, immobilized on zeolite PB Na-BEA zeolite, $10 \mathrm{mmol} \mathrm{HCOOH} / \mathrm{HCOONa}(9: 1), 1.3 \mathrm{~g}$ zeolite, $90{ }^{\circ} \mathrm{C}$, addition of $0.38 \mathrm{~mL} \mathrm{HCOOH}$ for recycling, compared to the aqueous homogeneous system: Entry 1, 6th recycling experiment in a aqueous homogeneous solution; Entries 2-7, catalyst absorbed on the zeolite

Table 1 Influence of the different zeolites as absorbents on the formic acid decomposition reaction rate, using the Ru-TPPTS catalyst

a The reproducibility is estimated to $\pm 5 \%$ from the first ten cycles

\begin{tabular}{lllll}
\hline Entry & Zeolites & $\begin{array}{l}\text { Quantity of } \\
\text { zeolites }(\mathrm{g})\end{array}$ & $\begin{array}{l}\text { Reaction } \\
\text { time }(\mathrm{min})^{*}\end{array}$ & $\begin{array}{l}\text { TOF } \\
\left(\mathrm{h}^{-1}\right)^{\mathrm{a}}\end{array}$ \\
\hline 1 & Z6-06-02 HUSY & 1.50 & 60 & 178 \\
2 & PB Na-BEA & 0.73 & 25 & 427 \\
3 & H-MOR-40 A & 1.50 & 60 & 178 \\
4 & EX 1350 & 1.80 & 60 & 178 \\
5 & PZ-2/50 H & 0.85 & 26 & 410 \\
\hline
\end{tabular}

polymers gave stable solid supports resulting heterogeneous catalysts for selective formic acid. The leaching of the metal was negligible and the catalysts could be easily separated from the reactant/solution, and could be reused directly. High activities could be achieved in the first several cycles with the ruthenium-TPPTS catalyst bound to the ion exchange resin although gradual deactivation was observed. The zeolites served as absorbents for the catalyst solution. Clearly, further work is required to optimize an immobilized catalyst as extensive catalyst lifetimes would be advantageous in most applications. Alternative ion exchange materials and more hydrophilic polymer systems are currently being evaluated in our laboratory and the outcome of these studies will be reported in due course.

Acknowledgment We are grateful to the Swiss National Science Foundation and the EPFL for financial support.

\section{References}

1. Dresselhaus MS, Thomas IL (2001) Nature 414:332

2. Williams LO (2002) An end to global warming. Pergamon, Oxford, pp 1-31 
3. Schlapbach L, Züttel A (2001) Nature 414:353

4. Bluhm ME, Bradley MG, Butterick R III, Kusari U, Sneddon LG (2006) J Am Chem Soc 128:7748

5. Fukuzumi S (2008) Eur J Inorg Chem 1351

6. Williams R, Crandall RS, Bloom A (1978) Appl Phys Lett 33:381

7. Ying DHS, Madix RJ (1978) Inorg Chem 17:1103

8. Xu C, Goodman DW (1996) J Phys Chem 100:245

9. Columbia MR, Crabtree AM, Thiel PA (1992) J Am Chem Soc 114:1231

10. Senanayake SD, Mullins DR (2008) J Phys Chem C 112:9744

11. Foster D, Beck GR (1971) Chem Commun 1072

12. Laine RM, Rinker RG, Ford PC (1977) J Am Chem Soc 99:252

13. Yoshida T, Okano T, Otsuka S (1980) J Am Chem Soc 102:5966

14. Gloaguen F, Lawrence JD, Rauchfuss TB (2001) J Am Chem Soc 123:9476

15. Garcia-Verdugo E, Liu Z, Ramirez E, Garcia-Serna J, Fraga-Dubreuil J, Hyde JR, Hamley PA, Poliakoff M (2006) Green Chem 8:359

16. Fellay C, Dyson PJ, Laurenczy G (2006) International patent application filed

17. Enthaler S (2008) ChemSusChem 1:801

18. Joo F (2008) ChemSusChem 1:805

19. Loges B, Boddien A, Junge H, Beller M (2008) Angew Chem Int Ed 47:3962

20. Boddien A, Loges B, Junge H, Beller M (2008) ChemSusChem 1:751

21. Junge H, Boddien A, Capitta F, Loges B, Noyes JR, Gladiali S, Beller M (2009) Tetrahedron Lett 50:1603

22. Loges B, Boddien A, Junge H, Noyes JR, Baumann W, Beller M (2009) Chem Commun 4185

23. Morris DJ, Clarkson GJ, Wills M (2009) Organometallics 28:4133

24. Fukuzumi S, Kobayashi T, Suenobu T (2008) ChemSusChem 1:827

25. Cole-Hamilton DJ (2003) Science 299:1702

26. Joó F (2001) Aqueous organometallic catalysis (catalysis by metal complexes), vol 23. Kluwer, Dordrecht

27. Adams DJ, Dyson PJ, Tavener SJ (2004) Chemistry in alternative reaction media. Wiley, Chichester

28. Bhanage BM, Ikushima Y, Shirai M, Arai M (1999) Chem Commun 1277-1278

29. Dyson PJ (2002) Appl Organomet Chem 16:495-500

30. Gladysz JA, Curran DP (2002) Tetrahedron 58:3823-3825

31. Dyson PJ, Ellis DJ, Laurenczy G (2003) Adv Synth Catal 345:211

32. Dwars T, Oehme G (2002) Adv Synth Catal 344:239-260

33. McMorn P, Hutchings GJ (2004) Chem Soc Rev 33:108-122

34. Cornils B, Herrmann WA (eds) (2004) Applied homogeneous catalysis with organometallic compounds, vol 1-3, 2nd edn. Wiley-VCH, Weinheim

35. Lu J, Toy PH (2009) Chem Rev 109:815-838

36. Barbaro P, Liguori F (2009) Chem Rev 109:515-529

37. End N, Schöning K-U (2004) Top Curr Chem 242:241-271

38. Fellay C, Dyson PJ, Laurenczy G (2008) Angew Chem Int Ed 47:3966

39. Hida S, Roman PJ, Bowden AA Jr, Atwood JD (1998) J Coord Chem 43:345-348

40. Cusanelli A, Frey U, Richens DT, Merbach AE (1996) J Am Chem Soc 118:5265

41. Elek J, Nadasdi L, Papp G, Laurenczy G, Joo F (2003) Appl Catal A 255:59

42. Fellay C, Yan N, Dyson PJ, Laurenczy G (2009) Chem Eur J 15:3752

43. Fyfe CA, Clark HC, Davies JA, Hayes PJ, Wasylishen RE (1983) J Am Chem Soc 105:6577-6584 